\title{
BMJ Open Impact of severe polyhandicap cared for at home on French informal caregivers' burden: a cross-sectional study
}

Marie-Christine Rousseau (10, , ${ }^{1,2}$ Karine Baumstarck, ${ }^{2}$ Maria Valkov, ${ }^{1}$ Agnés Felce, ${ }^{3}$ Catherine Brisse, ${ }^{4}$ Sherezad Khaldi-Cherif, ${ }^{5}$ Anderson Loundou, ${ }^{2}$ Pascal Auquier, ${ }^{2}$ Thierry Billette de Villemeur, ${ }^{6,7}$ The French Polyhandicap Group

To cite: Rousseau M-C, Baumstarck K, Valkov M, et al. Impact of severe polyhandicap cared for at home on French informal caregivers' burden: a cross-sectional study. BMJ Open 2020;10:e032257. doi:10.1136/ bmjopen-2019-032257

- Prepublication history and additional material for this paper are available online. To view these files, please visit the journal online (http://dx.doi. org/10.1136/bmjopen-2019032257).

Received 11 June 2019

Revised 22 November 2019 Accepted 02 December 2019

Check for updates

(c) Author(s) (or their employer(s)) 2020. Re-use permitted under CC BY-NC. No commercial re-use. See rights and permissions. Published by BMJ.

For numbered affiliations see end of article.

Correspondence to

Dr Marie-Christine Rousseau,

EA 3279, Self-perceived Health Assessment Research Unit, AixMarseille Universite, Marseille, France;

marie-christine.rousseau@ aphp.fr

\section{ABSTRACT}

Objectives Polyhandicap (PLH), defined by a combination of profound intellectual impairment and serious motor deficits, is a severe condition with complex disabilities. In France, care of the large majority of PLH individuals is managed in specialised rehabilitation centres or residential facilities, but some of PLH individuals are cared for at home. The aims of this study were to assess the self-perceived burden among informal caregivers of PLH individuals and to identify potential determinants of this burden.

Design Cross-sectional study (Neuropaediatric Department, Trousseau Hospital, Paris, France).

Settings PLH children were recruited from a specialised paediatric/neurological department.

Participants The selection criteria of caregivers were age above 18 years and being the PLH individual's next of kin. Outcomes measures From March 2015 to December 2016, data were collected from the caregivers, including sociodemographical data, health status, psychobehavioural data (quality of life, mood disorders and coping) and self-perceived burden. In addition, the health status of the PLH individual was collected. Relationships between the burden scores and potential determinants were tested (correlations coefficients, Mann-Whitney tests, generalised estimating equations models).

Results Eighty-four children were eligible; 77 families returned their questionnaire. The informal caregivers of PLH children experienced a high level of perceived burden (scores ranged from $55 \pm 20$ to $81 \pm 12$ ). Eighty per cent of them had more than 5 hours of daily caregiving and $51 \%$ of them had to get up more than twice during the night. The main factors associated with caregiver burden were age, financial issues, health status, daily care and coping strategies. The patients' health status was not associated with caregiver burden.

Conclusions Some of the caregiver burden determinants might be modifiable. These findings should help healthcare workers and health-decision makers implement specific and appropriate interventions.

Trial registration number NCT02400528.

\section{BACKGROUND}

Polyhandicap (PLH) is a severe health condition with complex disabilities. This chronic disorder occurs in an immature brain,
Strengths and limitations of this study

- This study explored, for the first time, the burden on the informal caregivers of polyhandicap (PLH) individuals cared for at home.

- This study was performed on a large sample allowing a high representativeness.

- These findings, based on a cross-sectional design, should be confirmed by longitudinal approaches.

- Based on a small sample size; our results may benefit from confirmation in a larger sample.

- Qualitative studies should be performed to better understand the determinants of PLH parents' burden.

leading to profound intellectual impairment and serious motor deficit. The result is an extreme restriction of autonomy and communication. The definition of PLH was adopted by the French scientific community and the French law (French Law no. 89-798, 27 October 1989, health policy of disability care). ${ }^{12}$ PLH is similar to profound intellectual and multiple disabilities, but it does not systematically refer to a disorder affecting an immature brain. ${ }^{3}$ In France, the prevalence of PLH is estimated in the paediatric population to be between 0.7 and 1.28 per thousand, and 880 new cases are diagnosed per year. ${ }^{4}$ Due to the various serious disabilities and multiple comorbidities, ${ }^{5}$ PLH patients need permanent human and technical assistance throughout their life.

The French health system allows these individuals to benefit from two main caremanagement modalities: specialised re-education centres, providing a high level of medical care for patients with the most severe health issues, and residential facilities, offering more educational care for less severely affected individuals. ${ }^{6}$ However, the care of some individuals, mainly children or young adults, is managed at home. Due to the improvement in life expectancy, the 
progressive move from traditional institutional care to deinstitutionalisation care, and a (slow) reduction in stigmatisation, family caregivers assume new roles that were previously carried out by institutional caregivers. Families of PLH children, from birth or in the first years of life of the individual, are repeatedly and chronically confronted with major nursing care and stressful situations. Despite being supported by human and technical assistance, the burden on families is likely to be considerable. Some studies have explored burden on informal caregivers who have children with multiple disabilities ${ }^{7-9}$ and in informal caregivers who have children with cerebral palsy. ${ }^{10-14}$ The caregivers reported deteriorated health status, financial difficulties, restriction in their social participation and physical overload. Limited data are available for caregivers of patients with PLH. ${ }^{15}{ }^{16}$ However, an assessment of parent burden and knowledge of which factors are determinants of this burden would strongly assist clinicians and health decision-making authorities in offering appropriate interventions such as human and technical assistance, respite and supportive care, and psychological support.

The aims of this study were as follows: (i) to describe the health profile of PLH individuals whose care is managed at home, (ii) to assess the burden on their informal caregivers and (iii) to identify potential determinants of caregiver burden.

\section{METHODS}

\section{Design and settings}

This study was based on a cross-sectional design and was included in the French national PLH study. The general aim of the French PLH study was to identify the potential (socioeconomical, environmental and epidemiological) determinants of the health status of PLH individuals and understand the daily life of their informal caregivers. PLH individuals with care managed at home were recruited from a specialised paediatric/neurological department of a university hospital (Neuropaediatric Department, Trousseau Hospital, Assistance Publique Hôpitaux de Paris, France).

\section{Selection criteria}

Eligible criteria of PLH individuals were severe PLH defined by the combination of motor deficiency (tetraparesis, hemiparesis, paraparesis, extrapyramidal syndrome, cerebellar syndrome and neuromuscular problems) and intellectual impairment $(\mathrm{I} Q 40)$, associated with everyday life dependence (functional independence measure (FIM) $<55$ ), restricted mobility (gross motor function classification system (GMFCS) levels III, IV and V), age at onset of cerebral lesion under 3 years old and care managed at home. The selection criteria of informal caregivers were as follows: aged above 18 years, the PLH individual's next of kin and voluntary consent to participate.

\section{General procedure}

For each PLH individual included in the study, data were collected from medical records obtained by a dedicated clinical research assistant and were checked by the patient's referent physician. Next of kin (individuals to contact for any medical, administrative and social issues) were systematically identified in the medical record. From 19 March 2015 to 31 December 2016, a booklet, including self-administered questionnaires, was sent by mail to each next of kin. To optimise participation, a prepaid return envelope addressed to the coordination team send with the booklet.

\section{Data collection}

Two sources of data were used: medical records and caregiver data.

1. Patient characteristics were collected from the medical records:

- Sociodemographics: age and gender.

- Aetiology: unknown versus known, progressive versus non-progressive disease.

- Global health severity: severe for patients who met all the following criteria: motor handicap (paraparesia or tetraparesia and/or extrapyramidal syndrome and/or severe general hypotonia), IQ $<25$, FIM $\leq 20$, and GMFCS IV and V; less severe for patients who did not meet these criteria.

- Global health stability: unstable for patients who met at least one of the following criteria: recurrent pulmonary infections ( $\geq 5$ /year), drug-resistant epilepsy ( $\geq 4$ seizures/month); stable for patients who did not meet any of these criteria.

- Medical devices: at least one device (including invasive mechanical ventilation, non-invasive mechanical ventilation, tracheotomy, nasogastric tube, gastrostomy, permanent urinary catheter, cerebrospinal fluid derivation and central venous catheter).

- Usual means of care: home care, specialised reeducation centre or residential facility.

2. Data collected from caregivers were recorded in a booklet, and included the following:

- Sociodemographical and professional status: age, gender, nature of the relationship with the patient, marital status (not single/single), in a couple with the patient's other parent, number of children, another disabled individual living at home, educational level, occupational status (employed/unemployed) and self-perceived financial status.

- Health: chronic diseases, hospitalisation episode during the last 2 years.

- Psycho-behavioural characteristics: (i) quality of life (QoL): assessed using the WHO Quality of Life (WHOQoL-BREF, brief version of the WHOQoL-100) questionnaire, a generic questionnaire used worldwide describing four domains: physical health, psychological health, social relationships and environment. All scores ranged between 0 and 100. Higher scores indicated a better QoL; (ii) anxiety-mood disorders, assessed using a Likert Scale ranging from 1 (absence) to 10 (very significant); (iii) coping, assessed using the Brief Coping Ori- 
entation to Problems Experienced Scale, exploring four dimensions that include social support, problem solving, avoidance and positive thinking. ${ }^{17}$ Scores ranged from 0 to 100 . High scores reflected a high tendency to implement the corresponding coping strategies.

- Burden: (i) specific ad hoc questions: number of children living at home, hours of daily caregiving and frequency of getting up during the night; (ii) self-perceived burden using the Caregiver Reaction Assessment (CRA) Scale, ${ }^{18}$ a 24 -item questionnaire describing five subscales: self-esteem (seven items), family support (five items), financial impact (three items), planning impact (five items) and health impact (four items). Scores ranged from 1 to 5 . For the self-esteem subscale, a higher score indicated that caregiving had a more positive impact; a score $\geq 4$ was used to indicate a high positive impact. For the other four subscales, higher scores indicated that caregiving had a more negative impact; a score $\geq 3$ was used to indicate a high negative impact. All the scores were linearised on a $0-100$ scale.

Additional information was collected and detailed in the online supplementary file (additional table 1).

\section{Consent to participate}

A written consent form was obtained for each participant.

\section{Statistical analysis}

The CRA scores were calculated according to the tool's scoring rules. Comparison of CRA scores between different subgroups (parent variables: gender, nature of the relationship with the patient, marital status, other disabled individuals at home, educational level, occupational status, financial status, chronic disease(s), hospitalisations, hours of daily caregiving, getting up during the night; patient variables: gender, severity, stability, medical devices) was performed using Mann-Whitney tests. Associations between CRA scores and continuous variables (age of parents, number of children, QoL scores, anxiety-mood score, coping scores, number of children at home, age of children) were analysed using Spearman's correlations. Multivariate analyses using generalised estimating equations models were performed to identify variables linked to CRA scores. In the models, each CRA score was considered to be a separate dependent variable. The independent variables relevant to the models were selected from the univariate analysis, based on a threshold $p$ value of $\leq 0.05$. The final models produced standardised beta coefficients, which represented the change in the $\mathrm{SD}$ of the dependent variable (CRA) resulting from a change of one SD in the various independent variables. Statistical analyses were performed using SPSS $\mathrm{N}^{\circ} 22$ software (IBM SPSS PASW Statistics). All tests were two-sided. The threshold for statistical significance was set at $\mathrm{p}<0.05$.

\section{Patient and public involvement}

Some parents of PLH patients were involved during the validation of the final data collection form to provide their opinions on the choice of questionnaires, understanding/formulation of the items, length of the form and so on. At the end of the study, a research clinical assistant contacted a sample of 50 non-respondents by phone to collect the reasons for non-participation (time consuming, language difficulties, avoidance and so on).

\section{RESULTS}

A total of 84 children were eligible. Seventy-seven of the families returned their questionnaires (response rate: $92 \%)$.

\section{Characteristics of the children}

The youngest child was 3 years old and the oldest was 27 years. The gender ratio was 1 . The PLH aetiology was unknown for $13 \%$ and progressive for $18 \%$. Almost $70 \%$ of the children presented with severe PLH and $42 \%$ of them presented with unstable disease. The developmental level according to the Brunet-Lezine Scale was low: 3-6 months for all domains. Approximately $30 \%$ of PLH children presented with visual impairment and 27\% presented with behavioural disorders. The most frequent comorbidities were epilepsy (52\%), scoliosis (41\%), gastro-oesophageal reflux (40\%), drooling (32\%), faecal impaction (31\%) and aspiration syndrome (23\%). The most prescribed medications were anticonvulsants, laxatives and osteoporotic prevention. Almost 30\% had at least one medical device. Eighty-two per cent of patients spent more than 3 hours daily positioned in sitting devices, $20 \%$ spent more than 3 hours daily in a verticalisation device and $4 \%$ spent more than 3 hours daily on an air mattress. Twenty-three per cent of the children had been admitted previously to the intensive care unit or the emergency department, and $4 \%$ of them were in a palliative condition. All characteristics of the children are described in tables 1 and 2.

\section{Characteristics of the informal caregivers}

The mean (SD) age of the participants was 41 (10) years. Most of the participants were the parents, usually the mothers. Ten per cent of the participants reported living with a second disabled individual. Half of them were employed and $34 \%$ of them self-reported financial difficulties. Almost $30 \%$ of the respondents reported at least one chronic disease and $23 \%$ reported a hospitalisation episode during the last 2 years. For support and financial assistance, $83 \%$ of the informal caregivers received a disability allowance, $10 \%$ received a disabled facility grant, $50 \%$ received a technical assistance allowance and almost $20 \%$ received human assistance at home. Twenty-two per cent of caregivers received psychological support, $43 \%$ had a social worker and $26 \%$ were involved in a disability association. Thirty-seven per cent of caregivers reported having a regular leisure activity and $44 \%$ took vacations. 
Table 1 Main characteristics of the children

\begin{tabular}{|c|c|}
\hline & \multirow{2}{*}{$\begin{array}{l}N=77 \\
N(\%)\end{array}$} \\
\hline & \\
\hline \multicolumn{2}{|l|}{ Gender } \\
\hline Boys & $38(49.4)$ \\
\hline Girls & $39(50.6)$ \\
\hline \multicolumn{2}{|l|}{ Age (years) } \\
\hline $\mathrm{M} \pm \mathrm{SD}$ & $7.8 \pm 5.7$ \\
\hline Med (IQR) & $5(4-11)$ \\
\hline \multicolumn{2}{|l|}{ Polyhandicap aetiology* } \\
\hline Unknown & $10(13.2)$ \\
\hline Known & $66(86.8)$ \\
\hline Progressive disease & $14(18.4)$ \\
\hline Non-progressive disease & $62(81.6)$ \\
\hline \multicolumn{2}{|l|}{ Severity† } \\
\hline Less severe & $24(31.2)$ \\
\hline Severe & $53(68.8)$ \\
\hline \multicolumn{2}{|l|}{ Stability $\ddagger$} \\
\hline Stable & $45(58.4)$ \\
\hline Unstable & $32(41.6)$ \\
\hline \multicolumn{2}{|l|}{ Medical devices } \\
\hline None & $54(70.1)$ \\
\hline At least one§ & $23(29.9)$ \\
\hline \multicolumn{2}{|l|}{ Usual care modality } \\
\hline Home care & 68 (88.3) \\
\hline Specalised re-education centre & $8(10.4)$ \\
\hline Residential facility & $1(1.3)$ \\
\hline
\end{tabular}

*One missing data.

†Severe case: association of motor handicap, IQ<25, FIM $\leq 20$ and GMFCS IV/N.

‡Unstable case: recurrent pulmonary infections and/or drugresistant epilepsy.

$\S A$ least one of the following list: gastrostomy (21), non-invasive mechanical ventilation (5), cerebrospinal fluid derivation (2), tracheotomia (1), permanent urinary probe $(0)$, nasogastric tube (0), invasive mechanical ventilation (0) and central venous catheter (0). FIM, functional independency measure; GMFCS, gross motor function classification system.

Almost $40 \%$ of families reported being satisfied with caregiver services and $37 \%$ of parents reported being somewhat satisfied with the medical information given. All the details are provided in table 3 and in the online supplementary additional table 1 .

\section{Burden on the informal caregivers}

For $80 \%$ of informal caregivers, the hours of daily caregiving were more than 5 hours per day; $51 \%$ of the informal caregivers had to get up more than twice during the night to care for the PLH individual. All CRA scores are described in table 3 .
Table 2 Detailed characteristics of the children

\begin{tabular}{l}
$\mathbf{N}=77$ \\
\hline $\mathrm{N}(\%)$ \\
\hline Med (IQR)
\end{tabular}

1. Health status

Neurodevelopment status (months)*

$\begin{array}{lc}\text { Language } & 5(2-9) \\ \text { Posture-motor ability } & 3(2-10) \\ \text { Coordination } & 6(2-6) \\ \text { Sociability } & 6(2-9) \\ \text { Neurological handicaps } & \\ \text { Severe dystonia } & 5(7.5) \\ \text { Global hypotonia } & 38(52.1) \\ \text { Extrapyramidal syndrome } & 13(19.1) \\ \text { Ataxia } & 5(7.5)\end{array}$

Sensorial disorders

Visual impairment

$22(28.9)$

Hearing impairment

7 (9.2)

Behavioural disorders $† 20(27.0)$

Sleep disorders

$\begin{array}{lc}\text { Night wake up } & 20(26.7) \\ \text { Difficulties falling asleep } & 12(16.2) \\ \text { Short sleep } & 3(4.2) \\ \text { Inversion } & 4(5.4)\end{array}$

Epilepsia

Presence of epilepsia $\quad 40$ (52.6)

At least one crisis per day 27 (67.5)

Previous status epilepticus $19(24.7)$

Orthopaedic

Scoliosis $31(41.3)$

Limb deformation 25 (34.2)

Hip luxation 11 (14.3)

Arthrodesis, other surgery $12(15.8)$

Pulmonary

Aspiration syndrome 18 (23.4)

Recurrent pulmonary infections 8 (10.4)

Digestive

Drooling

25 (32.5)

Faecal impaction

24 (31.2)

Gastro-oesophageal reflux

31 (40.3)

Urinary

Recurrent urinary tract infections $\quad 1$

Urinal retention 2

Cutaneous

Bedsores

1

2.Treatments and rehabilitation

Medications 
Table 2 Continued

\begin{tabular}{lc}
\hline & $\mathbf{N}=\mathbf{7 7}$ \\
\cline { 2 - 2 } & $\mathbf{N}(\%)$ \\
\cline { 2 - 2 } & Med (IQR) \\
\hline More than 3 & $35(45.4)$ \\
\hline Total number & $3(2-7)$ \\
\hline Laxatives & $42(54.5)$ \\
\hline Anticonvulsants & $48(62.3)$ \\
\hline Psychotropics & $7(9.1)$ \\
\hline Osteoporosis prevention & $15(19.5)$ \\
\hline Antispastics & $12(15.6)$ \\
\hline Antidystonics & $8(10.4)$ \\
\hline Devicesł & \\
\hline No device & $54(70.1)$ \\
\hline One device & $18(23.4)$ \\
\hline Two devices & $4(5.2)$ \\
\hline Four devices & 1 \\
\hline Vhours/day in a sitting device & $63(81.8)$ \\
\hline Verticalisation device use & $15(19.5)$ \\
\hline Air mattress & $11(14.3)$ \\
\hline 3.Health pathway & \\
\hline Previous emergency and/or ICU admission & $18(23.4)$ \\
\hline Perception of referent physician & \\
\hline Medical care inadequacy & $7(9.1)$ \\
\hline Educational care inadequacy & $12(15.6)$ \\
\hline Request for an admission in institution§ & $21(27.3)$ \\
\hline Life project structuration & $54(70.1)$ \\
\hline Palliative condition & $3(3.9)$ \\
\hline
\end{tabular}

Med (IQR): median (IQR).

*Neurodevelopmental status levels range from 0 to 24 months. †Behavioural disorders including intermittent screaming and/or agitation and/or stereotypies and/or intermittent crying and/or selfaggressivity and/or hetero-aggressivity.

‡Including gastrostomy, non-invasive mechanical ventilation, cerebrospinal fluid derivation, tracheotomia, permanent urinary probe, nasogastric tube, invasive mechanical ventilation and central venous catheter.

§Registered on a waiting list and/or official request made by the French Department for Persons with Disabilities.

ICU, intensive care unit.

\section{Factors associated with the informal caregivers' burden} scores

Relationships between self-perceived burden of caregivers and their characteristics

For each CRA dimension, the factors associated with burden were as follows: (1) worst self-esteem dimension: use of avoidance as a coping strategy; (2) worst familial support dimension: having a second disabled individual living at home, a previous hospitalisation episode, reports of lower QoL scores, reports of higher anxiety-mood disorder levels, less use of social support as a coping
Table 3 Characteristics of the informal caregivers

$\mathrm{N}=77$
$\mathrm{~N}(\%)$
$\mathrm{M} \pm \mathrm{SD}$
Med (IQR)

\begin{tabular}{ll}
\hline 1. Sociodemographics & \\
\hline Age (years) & $41.4 \pm 10.2$ \\
\hline Gender & $42(34-47)$ \\
$\quad$ Men & $28(36.8)$ \\
Women & $48(63.2)$
\end{tabular}

Nature of relationship with the PLH individual

Parents $69(89.6)$

Others* $7(9.1)$

Marital status

\begin{tabular}{ll} 
Not single & $65(84.4)$ \\
\multicolumn{1}{c}{ Single } & $11(14.3)$ \\
$\begin{array}{l}\text { Couple with the other parent of the PLH } \\
\text { individual }\end{array}$ & $57(74.0)$
\end{tabular}

Number of children $3(2-4)$

Other person with disability living home 8 (10.4)

Educational level

$\begin{array}{ll}<12 \text { years } & 35(45.5) \\ \geq 12 \text { years } & 42(54.5)\end{array}$

Occupational status

Not worker $38(49.4)$

Worker $38(49.4)$

Self-perceived financial status

$\begin{array}{ll}\text { Not difficult } & 49(63.6) \\ \text { Difficult } & 26(33.8)\end{array}$

2. Health N (\%)

Personal chronic disease(s) 22 (28.6)

Hospitalisation episode during the last $2 \quad 18$ (23.4) years

3. Psycho-behavorial characteristics $\quad \mathrm{N}(\%)$

Quality of life (WHOQoL scores) (0-100)†

Physical $\quad 61.5 \pm 19.3$

\begin{tabular}{ll} 
Psychological & $65.8 \pm 15.7$ \\
Social & $60.8 \pm 19.5$ \\
\hline Environmental & $58.7 \pm 13.9$
\end{tabular}

Anxiety-mood score (1-10)‡

Mean \pm SD $5.9 \pm 2.4$

Coping strategies (Brief-COPE scores) (0-100)§

$\begin{array}{ll}\text { Social support } & 39.5 \pm 19.7 \\ \text { Problem solvings } & 57.8 \pm 22.18 \\ \text { Avoidance } & 19.4 \pm 11.5\end{array}$

Continued 
Table 3 Continued

\begin{tabular}{|c|c|}
\hline & $\mathrm{N}=77$ \\
\hline & $\begin{array}{l}\mathbf{N}(\%) \\
\text { M.SD } \\
\text { Med (IQR) }\end{array}$ \\
\hline Positive thinking & $53.9 \pm 20.2$ \\
\hline 4. Burden & $\mathrm{N}(\%)$ \\
\hline Number of children living at home & $2(2-3)$ \\
\hline \multicolumn{2}{|l|}{ Daily time caregiving (hours) } \\
\hline$\leq 4$ & $16(20.8)$ \\
\hline$(5-8)$ & $26(33.8)$ \\
\hline$\geq 9$ & $30(39.0)$ \\
\hline \multicolumn{2}{|l|}{ Get up during night } \\
\hline Never & $10(13.0)$ \\
\hline 1 & $23(29.9)$ \\
\hline$\geq 2$ & $39(50.7)$ \\
\hline \multicolumn{2}{|l|}{$\begin{array}{l}\text { Self-perceived reaction (CRA scores) } \\
\text { impact }(0-100)\end{array}$} \\
\hline Self-esteem & $81.1 \pm 11.5$ \\
\hline Familial support** & $53.1 \pm 17.7$ \\
\hline Financial $^{\star \star}$ & $59.4 \pm 21.7$ \\
\hline Scheduling/planification ${ }^{\star *}$ & $69.7 \pm 18.4$ \\
\hline Health** & $55.1 \pm 19.9$ \\
\hline
\end{tabular}

*Others: 2 aunts, 2 grand-parents, 1 sibling, 1 cousin, 1 extrafamilial relationship.

†Higher scores: higher QoL level.

†Higher score: higher anxiety/mood disorder.

$\S$ Higher scores: higher use of the strategy.

१100: best self-esteem.

**100: worse familial support, worse financial impact, worse planification impact, worse health impact.

Brief-COPE, Brief Coping Orientation to Problems Experienced Scale; CRA, caregiver reaction assessment; PLH, polyhandicap; WHOQoL, WHO Quality of Life.

strategy, reports of longer hours of daily caregiving and getting up more than once during the night; (3) worst financial dimension: being older, having a second disabled individual at home, reports of financial difficulties, having an individual with a chronic disease, reports of lower QoL score, less use of positive thinking as a coping strategy; (4) worst planning dimension: previous personal hospitalisation episode, reports of lower QoL scores, reports of higher anxiety-mood disorder levels, use of avoidance as coping strategy, reports of longer hours of daily caregiving and reports of getting up more than once during the night; (5) worst health dimensions: being older, having a personal chronic disease, reports of lower QoL scores, reports of higher anxiety-mood disorder levels, use of avoidance as coping strategy and reports of getting up more than once during the night. The details are described in table 4 .
Relationships between self-perceived burden on caregivers and the PLH individual's characteristics

Age, gender, severity and stability of the disease, and medical devices did not modulate the self-esteem, financial and planning dimensions. The older the PLH individual was, the worse the familial and the health scores were. Family support was worst when the PLH individual was male. Details are described in table 5. Additional links are provided in online supplementary additional table 2.

\section{The most important predictors of burden}

After adjustment, the factors associated with CRA scores were as follows: (1) worst familial support dimension: less use of social support as a coping strategy, getting up more than once during the night and older age of the PLH person; (2) worst financial dimension: having a second disabled individual at home and lower QoL score; (3) worst planification dimension: lower QoL scores and getting up more than once during the night; (4) worst health dimensions: having a personal chronic disease, lower QoL scores, higher anxiety-mood disorder levels, getting up more than once during the night and age of the PLH individual. No adjustment was performed on the self-esteem score (only one variable with a $\mathrm{p}$ value $<0.05$ in the univariate analysis). The details are described in online supplementary additional table 3

\section{DISCUSSION}

Our study explores, for the first time, the burden of the informal caregivers of PLH individuals whose care is managed at home. Our results are in line with the findings from various countries, reported in the meta-synthesis conducted by Dantas et al, showing that parents and families of children with multiple disabilities experience difficulties resulting from the burden of care (health problems, limitations to others activities, increased financial costs).${ }^{9}$ The negative financial impact and the negative planification impact were the most affected dimensions, as previously reported by informal caregivers of patients with other conditions: patients with traumatic brain injury, ${ }^{19}$ amyotrophic lateral sclerosis, ${ }^{20}$ cancer $^{21} 22$ and chronic illness. ${ }^{21}$ However, considering that caregiver burden may be defined by positive or negative feelings that may be experienced when giving care, ${ }^{23}$ we also found a substantial positive impact on self-esteem. This finding was previously reported in other complex conditions: caregivers of blind children, ${ }^{24}$ traumatic brain injury patients, ${ }^{19}$ amyotrophic lateral sclerosis patients ${ }^{20}$ and cancer patients. ${ }^{21}{ }^{22}$ It is increasingly recognised that the caregiving experience is not only associated with negative consequences, but can result in subjective gains and satisfaction, ${ }^{25}$ promote a sense of accomplishment and companionship, and improve self-esteem. The weight of the burden on our sample was very close to those of caregivers of patients with traumatic brain injury, ${ }^{19}$ but it was higher than caregivers of cancer patients (Maguire 2016, data not published). We hypothesise that the median age, 
Table 4 Relationships between self-perceived burden of caregivers and their own characteristics

$\frac{\text { Self-esteem }}{(0-100)^{*}} \frac{\text { Familial support }}{(0-100) \dagger} \frac{\text { Financial }}{(0-100) \dagger} \frac{\text { Planification }}{(0-100) \dagger} \frac{\text { Health }}{(0-100) \dagger}$

Sociodemographics

Age

\begin{tabular}{|c|c|c|c|c|c|}
\hline $\mathrm{R}$ & 0.076 & 0.253 & $0.298^{*}$ & 0.113 & $0.265^{*}$ \\
\hline$P$ value & 0.568 & 0.055 & 0.022 & 0.393 & 0.043 \\
\hline \multicolumn{6}{|l|}{ Gender } \\
\hline Women & $80.7 \pm 11.6$ & $51.5 \pm 17.6$ & $56.1 \pm 21.4$ & $68.2 \pm 19.1$ & $55.7 \pm 20.9$ \\
\hline Men & $81.5 \pm 11.5$ & $55.8 \pm 17.9$ & $65.1 \pm 21.2$ & $72.1 \pm 17.2$ & $53.8 \pm 18.1$ \\
\hline$P$ value & 0.822 & 0.487 & 0.103 & 0.495 & 0.737 \\
\hline \multicolumn{6}{|c|}{ Nature of relationship } \\
\hline Mothers & $81.4 \pm 11.1$ & $52.2 \pm 17.8$ & $55.2 \pm 22.6$ & $70.2 \pm 19.4$ & $56.3 \pm 21.5$ \\
\hline Fathers & $81.6 \pm 11.7$ & $56.1 \pm 18.2$ & $64.5 \pm 21.4$ & $73.1 \pm 16.8$ & $53.6 \pm 18.5$ \\
\hline$P$ value & 0.958 & 0.536 & 0.112 & 0.710 & 0.636 \\
\hline \multicolumn{6}{|l|}{ Marital status } \\
\hline Single & $83.3 \pm 11.0$ & $57.0 \pm 12.0$ & $59.3 \pm 24.4$ & $72 \pm 18.8$ & $59.0 \pm 21.0$ \\
\hline Not single & $80.6 \pm 11.6$ & $52.3 \pm 18.5$ & $59.3 \pm 21.3$ & $69.2 \pm 18.4$ & $54.3 \pm 19.7$ \\
\hline$P$ value & 0.486 & 0.323 & 0.852 & 0.530 & 0.556 \\
\hline \multicolumn{6}{|c|}{ Number of children } \\
\hline $\mathrm{R}$ & 0.064 & 0.098 & 0.144 & 0.082 & 0.043 \\
\hline$P$ value & 0.605 & 0.433 & 0.245 & 0.511 & 0.729 \\
\hline
\end{tabular}

Other person with disability at home

\begin{tabular}{|c|c|c|c|c|c|}
\hline No & $81.2 \pm 11.6$ & $51.8 \pm 17.6$ & $57.5 \pm 21.3$ & $68.7 \pm 18.4$ & $54.0 \pm 20.3$ \\
\hline Yes & $79.0 \pm 11.3$ & $66 \pm 14.0$ & $80 \pm 13.9$ & $79.3 \pm 16.4$ & $65.8 \pm 8.01$ \\
\hline$P$ value & 0.614 & 0.046 & 0.012 & 0.131 & 0.088 \\
\hline \multicolumn{6}{|c|}{ Educational level } \\
\hline$<12$ years & $82.1 \pm 11.1$ & $56.1 \pm 16.3$ & $61.8 \pm 24.1$ & $70.1 \pm 19.7$ & $58.5 \pm 22.4$ \\
\hline$\geq 12$ years & $80.2 \pm 11.8$ & $50.8 \pm 18.5$ & $57.3 \pm 19.6$ & $69.2 \pm 17.6$ & $52.4 \pm 17.5$ \\
\hline$P$ value & 0.335 & 0.114 & 0.347 & 0.749 & 0.226 \\
\hline \multicolumn{6}{|c|}{ Occupational status } \\
\hline Worker & $79.7 \pm 11.4$ & $52.3 \pm 20.4$ & $60 \pm 20.2$ & $70.2 \pm 18.4$ & $56.1 \pm 19.2$ \\
\hline Not worker & $82.4 \pm 11.6$ & $53.7 \pm 14.8$ & $59.0 \pm 23.4$ & $69.7 \pm 18.4$ & $54.1 \pm 20.9$ \\
\hline$P$ value & 0.205 & 0.588 & 0.843 & 0.972 & 0.568 \\
\hline \multicolumn{6}{|c|}{ Self-perceived financial status } \\
\hline Not difficult & $80.3 \pm 12.2$ & $52.3 \pm 18.5$ & $54.0 \pm 20.2$ & $67.6 \pm 19.5$ & $53.9 \pm 20.7$ \\
\hline Difficult & $82.3 \pm 10.2$ & $54.3 \pm 16.5$ & $68.9 \pm 21.2$ & $73.4 \pm 15.7$ & $57.2 \pm 18.4$ \\
\hline$P$ value & 0.425 & 0.737 & 0.005 & 0.209 & 0.510 \\
\hline \multicolumn{6}{|l|}{ Health } \\
\hline \multicolumn{6}{|c|}{ Personal chronic disease(s) } \\
\hline No & $81.7 \pm 10.8$ & $52.1 \pm 18.4$ & $55.3 \pm 22.1$ & $68.8 \pm 19.4$ & $51.3 \pm 18.8$ \\
\hline Yes & $79.3 \pm 13.1$ & $55.4 \pm 15.9$ & $69.2 \pm 17.4$ & $71.8 \pm 15.7$ & $64.7 \pm 19.5$ \\
\hline$P$ value & 0.549 & 0.449 & 0.015 & 0.705 & 0.006 \\
\hline \multicolumn{6}{|c|}{$\begin{array}{l}\text { Hospitalisation during the last } 24 \\
\text { months }\end{array}$} \\
\hline No (55) & $81.4 \pm 12.2$ & $50.1 \pm 16.9$ & $56.7 \pm 22.4$ & $67.1 \pm 18.3$ & $52.7 \pm 19.7$ \\
\hline Yes (18) & $79.8 \pm 9.16$ & $61.7 \pm 17.5$ & $67.4 \pm 17.2$ & $77.3 \pm 17.0$ & $61.9 \pm 19.1$ \\
\hline
\end{tabular}


Table 4 Continued

\begin{tabular}{|c|c|c|c|c|c|}
\hline & Self-esteem & Familial support & Financial & Planification & Health \\
\hline & $(0-100)^{*}$ & $(0-100) \dagger$ & $(0-100) \dagger$ & $(0-100) \dagger$ & $(0-100) \dagger$ \\
\hline$P$ value & 0.383 & 0.014 & 0.099 & 0.021 & 0.153 \\
\hline \multicolumn{6}{|c|}{ Psycho-behavorial characteristics } \\
\hline \multicolumn{6}{|l|}{ Quality of life } \\
\hline Physical & 0.010 & $-0.471 \dagger$ & $-0.554 \dagger$ & $-0.465 \dagger$ & $-0.544 \dagger$ \\
\hline$P$ value & 0.930 & $<0.001$ & $<0.001$ & $<0.001$ & $<0.001$ \\
\hline Psychological & 0.116 & $-0.421 \dagger$ & $-0.354 \dagger$ & $-0.352 \dagger$ & $-0.405 \dagger$ \\
\hline$P$ value & 0.328 & $<0.001$ & 0.002 & 0.002 & $<0.001$ \\
\hline Social & -0.003 & $-0.468 \dagger$ & $-0.336 \dagger$ & $-0.441 \dagger$ & $-0.425 \dagger$ \\
\hline$P$ value & 0.981 & $<0.001$ & 0.004 & $<0.001$ & $<0.001$ \\
\hline Environmental & 0.132 & $-0.405 \dagger$ & $-0.552 \dagger$ & $-0.400 \dagger$ & $-0.469 \dagger$ \\
\hline$P$ value & 0.265 & $<0.001$ & $<0.001$ & 0.001 & $<0.001$ \\
\hline \multicolumn{6}{|l|}{ Anxiety-mood } \\
\hline $\mathrm{R}$ & 0.061 & $0.240^{*}$ & 0.165 & $0.269^{*}$ & $0.378 \dagger$ \\
\hline$P$ value & 0.613 & 0.043 & 0.168 & 0.024 & 0.001 \\
\hline \multicolumn{6}{|l|}{ Coping } \\
\hline Social support & -0.111 & $-0.311 \dagger$ & -0.184 & 0.016 & -0.089 \\
\hline$P$ value & 0.353 & 0.009 & 0.121 & 0.892 & 0.457 \\
\hline Problem solvings & 0.026 & -0.085 & -0.160 & -0.024 & -0.166 \\
\hline$P$ value & 0.832 & 0.487 & 0.183 & 0.843 & 0.166 \\
\hline Avoidance & $-0.296^{*}$ & 0.230 & 0.176 & $0.237^{*}$ & $0.328 \dagger$ \\
\hline$P$ value & 0.013 & 0.059 & 0.144 & 0.048 & 0.006 \\
\hline Positive thinking & 0.131 & -0.235 & $-0.277^{\star}$ & -0.093 & -0.233 \\
\hline$P$ value & 0.274 & 0.052 & 0.019 & 0.439 & 0.051 \\
\hline \multicolumn{6}{|l|}{ Burden } \\
\hline \multicolumn{6}{|c|}{ Number of children living at home } \\
\hline $\mathrm{R}$ & 0.027 & -0.105 & 0.042 & 0.007 & -0.067 \\
\hline$P$ value & 0.837 & 0.425 & 0.750 & 0.956 & 0.609 \\
\hline \multicolumn{6}{|c|}{ Daily caregiving (hours) } \\
\hline$\leq 4$ & $78.9 \pm 11.4$ & $48.5 \pm 16.2$ & $54.1 \pm 21.0$ & $60 \pm 12.0$ & $50 \pm 17.9$ \\
\hline $5-8$ & $82.4 \pm 11.5$ & $48.6 \pm 17.9$ & $57.1 \pm 19.2$ & $66.7 \pm 20.7$ & $51.1 \pm 17.7$ \\
\hline$\geq 9$ & $80.5 \pm 11.7$ & $59.5 \pm 17.1$ & $64.2 \pm 23.9$ & $76.9 \pm 16.5$ & $61.2 \pm 21.8$ \\
\hline$P$ value & 0.629 & 0.037 & 0.269 & 0.007 & 0.092 \\
\hline \multicolumn{6}{|c|}{ Get up night (number) } \\
\hline$<2$ & $81.5 \pm 10.5$ & $46 \pm 15.6$ & $54.5 \pm 21.6$ & $61.2 \pm 18.0$ & $48.9 \pm 19.7$ \\
\hline$\geq 2$ & $81.0 \pm 12.2$ & $58.7 \pm 17.6$ & $63.2 \pm 21.4$ & $76.2 \pm 15.4$ & $60 \pm 18.8$ \\
\hline$P$ value & 0.982 & 0.003 & 0.097 & $<0.001$ & 0.033 \\
\hline \multicolumn{6}{|l|}{ Assistance } \\
\hline \multicolumn{6}{|l|}{ Technical assistance } \\
\hline No & $78.45 \pm 9.932$ & $57.66 \pm 16.71$ & $66.11 \pm 20.13$ & $78 \pm 13.95$ & $61.45 \pm 21.64$ \\
\hline Yes & $81.19 \pm 12.41$ & $50.05 \pm 16.35$ & $58.14 \pm 21.88$ & $66.05 \pm 18.08$ & $51.42 \pm 15.69$ \\
\hline$P$ value & 0.265 & 0.060 & 0.145 & 0.013 & 0.072 \\
\hline \multicolumn{6}{|l|}{ Human assistance } \\
\hline No & $79.18 \pm 12.14$ & $53.75 \pm 17.52$ & $62.99 \pm 20.99$ & $71.33 \pm 18.25$ & $55.83 \pm 19.46$ \\
\hline Yes & $84.61 \pm 6.339$ & $50.46 \pm 16.29$ & $54.35 \pm 21.05$ & $66.46 \pm 16.37$ & $54.61 \pm 15.20$ \\
\hline
\end{tabular}

Continued 
Table 4 Continued

\begin{tabular}{|c|c|c|c|c|c|}
\hline & Self-esteem & Familial support & Financial & Planification & Health \\
\hline & $(0-100)^{*}$ & $(0-100) \dagger$ & $(0-100) \dagger$ & $(0-100) \dagger$ & $(0-100) \dagger$ \\
\hline $\mathrm{P}$ value & 0.133 & 0.590 & 0.170 & 0.368 & 0.846 \\
\hline
\end{tabular}

R: correlation coefficent

Bold values: $p$-value $<0.05$

*100: best self-esteem.

†100: worse familial support, worse financial impact, worse planification impact, worse health impact.

dependence level and disease evolution of PLH individuals (and, consequently, caregiver burden) are similar to patients with traumatic brain injury, but very different from those of cancer patients who are generally older, less dependent and have less hope of recovery. We found that PLH individuals whose care is managed at their parents' home were young, and presented with a severe and instable PLH with a decompensation of the health status, which may require acute and emergency care. This combination requires the permanent availability of caregivers in a stressful context, which naturally causes burden.

The second part of our findings refers to the factors associated with the burden on informal caregivers. Identifying burden determinants may help identify unmet needs, prioritise service improvements and support funding decisions. Sociodemographical, health and psychobehavioural determinants were explored. Contrary to similar studies, ${ }^{26}$ our results showed that the main sociodemographical and socioeconomical parameters (such as gender, marital status, educational level and occupational status) were not identified as significant burden determinants. We only found ectopic (and expected) associations. First, we found that health burden was most significant for older caregivers. Complete dependence of the PLH individuals may result in major care and the need to mobilise the patients several times per day (caring,

Table 5 Relationships between self-perceived burden of caregivers and the characteristics of the polyhandicap child

\begin{tabular}{|c|c|c|c|c|c|}
\hline & Self-esteem & Familial support & Financial & Planification & Health \\
\hline & $(0-100)^{*}$ & $(0-100) \dagger$ & $(0-100) \dagger$ & $(0-100) \dagger$ & $(0-100) \dagger$ \\
\hline \multicolumn{6}{|l|}{ Age } \\
\hline $\mathrm{R}$ & -0.002 & $0.263^{*}$ & 0.160 & 0.099 & $0.319 \dagger$ \\
\hline$P$ value & 0.984 & 0.027 & 0.176 & 0.406 & 0.006 \\
\hline \multicolumn{6}{|l|}{ Gender } \\
\hline Boys & $79.3 \pm 9.98$ & $59.4 \pm 17.2$ & $60.1 \pm 20.8$ & $73.2 \pm 17.6$ & $57.2 \pm 20.9$ \\
\hline Girls & $82.8 \pm 12.9$ & $46.5 \pm 15.9$ & $58.4 \pm 22.8$ & $65.6 \pm 18.6$ & $52.6 \pm 18.6$ \\
\hline$P$ value & 0.156 & 0.002 & 0.764 & 0.087 & 0.441 \\
\hline \multicolumn{6}{|l|}{ Severity } \\
\hline Less severe & $79.6 \pm 10.9$ & $57.2 \pm 17.3$ & $64.4 \pm 22.2$ & $74.8 \pm 18.0$ & $59.5 \pm 18.8$ \\
\hline Severe & $81.7 \pm 11.8$ & $51.0 \pm 17.7$ & $56.8 \pm 21.1$ & $67.0 \pm 18.2$ & $52.8 \pm 20.2$ \\
\hline$P$ value & 0.387 & 0.171 & 0.129 & 0.077 & 0.164 \\
\hline \multicolumn{6}{|l|}{ Stability } \\
\hline Stable & $80.9 \pm 12.1$ & $53.2 \pm 17.6$ & $59.3 \pm 23.0$ & $70.6 \pm 19.3$ & $57.4 \pm 21.5$ \\
\hline Unstable & $81.1 \pm 10.7$ & $52.8 \pm 18.1$ & $59.3 \pm 19.9$ & $68.1 \pm 17.2$ & $51.5 \pm 16.8$ \\
\hline$P$ value & 0.884 & 0.829 & 0.861 & 0.475 & 0.249 \\
\hline \multicolumn{6}{|l|}{ Medical } \\
\hline None & $80.7 \pm 12.1$ & $51.3 \pm 16.6$ & $59.4 \pm 22.0$ & $68.3 \pm 17.7$ & $54.5 \pm 19.6$ \\
\hline \multicolumn{6}{|l|}{ Device } \\
\hline At least one & $82 \pm 9.94$ & $57.4 \pm 19.9$ & $59 \pm 21.2$ & $73.2 \pm 20.1$ & $56.5 \pm 21.0$ \\
\hline$P$ value & 0.642 & 0.246 & 0.980 & 0.201 & 0.825 \\
\hline
\end{tabular}

R: correlation coefficient

Bold values: $p$-values $<0.05$

${ }^{*} 100$ : best self-esteem.

†100: worse familial support, worse financial impact, worse planification impact, worse health impact. 
moving, positioning patients and so on). ${ }^{16}$ As caregivers age, the burden may increase: families are likely to keep their child at home during the early years, but, as they get older, they are no longer able to take care of them and request the placement of their child in an institution. Some factors modulated burden related to the financial aspects: being older, reports of financial difficulties and caring for a second disabled individual (10\% of caregivers cared for a second disabled individual living at home as well as the PLH child). Families were often confronted with reduced financial resources related to work (absence or unstable employment due to time-consuming care) and the necessary expenses for outdoor/indoor facilities or any specialised equipment (eg, wheelchairs). This financial burden deserves the attention of health authorities. While various types of financial assistance in France are proposed to families, they are often confronted with administrative barriers and long lead times. These procedures should be simplified to meet the needs of the families.

As expected, ${ }^{11} 2728$ the caregivers' health status (having a chronic disease, reports of a recent hospitalisation episode, deteriorated emotional status) was related to their reported burden. Preserving caregiver health is a noteworthy issue both for caregivers and, indirectly, for patient health. Health awareness initiative and future health actions should be devised to prevent, diagnose and treat any health (including mental) problems of caregivers.

Psycho-behavioural aspects were strong factors in the modulation of the caregiver burden. First, we found, as reported in previous studies, that QoL, and all its components, was negatively associated with burden. This is supported by previous studies in other contexts, such as caregivers of individuals with mental illness, ${ }^{29}{ }^{30}$ and also caregivers of children with intellectual disability. ${ }^{28} 31$ Burden of care and QoL are considered by some authors to be closely related; however, from a theoretical perspective, burden of care and QoL do not measure the same aspects. Caregivers' burden of care is usually defined by its impacts and consequences on caregivers, and there is a negative conceptualisation of caregiving. However, QoL is not a direct conceptualisation of caregiving and proposes a global assessment of the general well-being of individuals. $^{32} 33$

More interestingly and surprisingly, the nature of the coping strategies used played a consequential role in the individual's burden modulation. The association between using avoidance as a coping strategy with worse individual outcomes has been described previously in many various contexts, such as cancer ${ }^{34}$ or severe mental illnesses ${ }^{35}$ and also in institutional caregivers of PLH individuals. ${ }^{36}$ In contrast, a positive-thinking strategy arose as a protective strategy for burden. A more systematic assessment of coping methods should identify individuals who do not use healthy coping strategies. Targeted psychological interventions based on psychoeducation and cognitive behavioural therapy may be offered to them. ${ }^{37}{ }^{38}$ Interventions based on problem solving or positive thinking have revealed predictors of satisfactory wellbeing in caregivers. ${ }^{39} 40$

The objective components of burden were partially related to the subjective self-perceived burden. As previous studies have shown, hours of daily caregiving are associated with greater burden. ${ }^{71}$ Nocturnal caregiving, which required getting up during the night several times, seemed to be a risk factor for burden. This result suggests the need for reinforcement of human assistance for home care and rest, which consequently may improve caregiver burden. This emphasises the need to maintain specialised institutions allowing alternation between the home and the institution to increase caregivers' free time and respite time while maintaining a family unit and a relationship with the PLH individual. We should be attentive to the various disability policies, according to the principles outlined in the United Nations Convention on the Rights of Individuals with Disabilities ('Disabilities.fr'), which promote a move towards deinstitutionalisation in favour of proximity services, possibly leading to caregiver burden. ${ }^{9}$

Surprisingly, the health status of PLH individuals in terms of severity, stability, medical device and neurodevelopmental status was not associated with the degree of caregiver burden. We can hypothesise that the difficult experience of caring for a PLH child may cause burden and overshadow all other health conditions. However, as the PLH individual aged, the burden level rose, which could be explained by the probable older age of caregivers. An interesting genre difference emerged in the lack of familial support for caregiving: parents of male individuals had less individual support than parents of female individuals confirming our previous results, which demonstrated a lower QoL for the parents of a male child than parents of a female child. ${ }^{27}$ This finding referred to the social representations that individuals develop. There is a longstanding and well-documented observation of boy-girl differences in parental affective investments with a male gender 'preference'. ${ }^{42}$ Future qualitative studies should further explore these aspects.

\section{Strengths and limitations}

One of the limitations of our study was the small sample size. Our results may benefit from confirmation in a larger sample in the future. However, this is the first study to document the perceived burden on this population of caregivers. This study was based on a cross-sectional design, which did not allow for causality inferences to be made between the studied factors and caregiver burden. Longitudinal designs allow for causality inferences.

\section{CONCLUSION}

This work demonstrated that the caregivers of PLH patients whose care was managed at home experienced a high perceived burden. The main determinants associated with this burden were factors related to the caregivers 
themselves (age, health issues and psycho-behavioural aspects), while factors related to the PLH individual were insignificant. Due to the modifiable nature of some of these determinants, detection, prevention and therapeutic strategies should be implemented.

\section{Author affiliations}

${ }^{1}$ Hôpital San Salvadour, Assistance Publique - Hôpitaux de Paris, Paris, Île-deFrance, France

${ }^{2}$ EA 3279, Self-perceived Health Assessment Research Unit, Aix-Marseille

Universite, Marseille, France

${ }^{3}$ Hôpital Marin d'Hendaye, Assistance Publique Hopitaux de Paris, Paris, Île-deFrance, France

${ }^{4}$ Comité d'Études, d'Éducation et de Soins Auprès des Personnes Polyhandicapées, Paris, France

${ }^{5}$ UGECAM lle de France, Paris, Île-de-France, France

${ }^{6}$ Hôpital de La Roche Guyon, Assistance Publique - Hopitaux de Paris, Paris, Île-deFrance, France

${ }^{7}$ Pathologie du développement, Sorbonne Université, UPMC, GRC ConCer-LD, Paris, France

Acknowledgements The French Polyhandicap Group includes the following individuals: Tanguy Leroy, Souhali Haddadou, Cécile Freihuber, Julie Bonheur, Stéphanie Valence, Marie-Christine Nougues, Laurent Luciani, Jean-Pierre Nouet, Catherine Coiffier, Philippe Sellier, Sophie Mathieu, Moustafa Ardati, Delphine Héron, Alexandra Afenjar, Diana Rodriguez, Diana Doummar, Marie-Laure Moutard, Daniel Willocq, Stéphane Pietra, Stéphane Lenormand, Elizabeth Grimont. The authors are grateful to Claire Morando for her logistical support.

Collaborators The French Polyhandicap Group includes the following individuals: Tanguy Leroy, Souhali Haddadou, Cécile Freihuber, Julie Bonheur, Stéphanie Valence, Marie-Christine Nougues, Laurent Luciani, Jean-Pierre Nouet, Catherine Coiffier, Philippe Sellier, Sophie Mathieu, Moustafa Ardati, Delphine Héron, Alexandra Afenjar, Diana Rodriguez, Diana Doummar, Marie-Laure Moutard, Daniel Willocq, Stéphane Pietra, Stéphane Lenormand, Elizabeth Grimont.

Contributors Conception and design: M-CR, TBV, PA. Study coordination: M-CR, TBV, KB, PA. Acquisition of data: M-CR, TBV, MV, SK-C, AF, CB, French Polyhandicap Group. Analysis of data: M-CR, KB, AL. Interpretation of data: M-CR, TBV, KB, PA. Drafting and writing of manuscript: $\mathrm{M}-\mathrm{CR}, \mathrm{KB}$. Revision and approval of final version of the manuscript: M-CR, TBV, MV, SK-C, AF, CB, KB, PA.

Funding This work is financially supported by French PREPS (Programme de recherche sur la performance du système de soins, year 2013) and the French Institut National de la Santé et de la Recherche Médicale (INSERM, year 2013): Grant DGOS and INSERM. The sponsor was represented by Assistance Publique, Hôpitaux de Marseille, France; and its role was to control the appropriateness of ethical and legal considerations.

Competing interests None declared.

Patient consent for publication Not required

Ethics approval Regulatory monitoring was performed according to the French law that requires the approval of the French ethics committee (Comite de Protection des Personnes Sud Méditerranée V, 20/10/2014, reference number 2014-A00953-44).

Provenance and peer review Not commissioned; externally peer reviewed.

Data availability statement Data are available upon reasonable request.

Open access This is an open access article distributed in accordance with the Creative Commons Attribution Non Commercial (CC BY-NC 4.0) license, which permits others to distribute, remix, adapt, build upon this work non-commercially, and license their derivative works on different terms, provided the original work is properly cited, appropriate credit is given, any changes made indicated, and the use is non-commercial. See: http://creativecommons.org/licenses/by-nc/4.0/.

\section{ORCID iD}

Marie-Christine Rousseau http://orcid.org/0000-0002-8065-8667
REFERENCES

1 I. Handicaps rares - Contextes, enjeux et perspectives 2013.

2 French law $n^{\circ} 89-798,1989$ October 27 th related to health policy of care disability.

3 Rousseau MC, Mathieu S, Brisse C, et al. Aetiologies, comorbidities and causes of death in a population of 133 patients with polyhandicaps cared for at specialist rehabilitation centres. Brain Inj 2015;29:837-42.

4 Rumeau-Rouquette C, du Mazaubrun C, Cans C, et al. [Definition and prevalence of school-age multi-handicaps]. Arch Pediatr 1998;5:739-44.

5 Motawaj M, Mathieu S, Brisse C, et al. Le décès des patients polyhandicapés: l'expérience du service de pédiatrie spécialisée pour polyhandicapés de La Roche-Guyon. JPP Ed Journ Parisiennes Pédiatrie 2010:267-71.

6 Rousseau M-C, Billette de Villemeur T, Khaldi-Cherif S, et al. Adequacy of care management of patients with polyhandicap in the French health system: a study of 782 patients. PLoS One 2018;13:e0199986.

7 Crabb C, Owen R, Stober K, et al. Longitudinal appraisals of family caregiving for people with disabilities enrolled in Medicaid managed care. Disabil Rehabil 2019;99:1-8.

8 Seliner B, Latal B, Spirig R. When children with profound multiple disabilities are hospitalized: a cross-sectional survey of parental burden of care, quality of life of parents and their hospitalized children, and satisfaction with family-centered care. J Spec Pediatr Nurs 2016;21:147-57.

9 Dantas KO, Neves RdaF, Ribeiro KSQS, et al. Repercussions on the family from the birth and care of children with multiple disabilities: a qualitative meta-synthesis. Cad Saude Publica 2019;35:e00157918.

10 Barabas G, Matthews WS, Zumoff P. Care-load for children and young adults with severe cerebral palsy. Dev Med Child Neurol 1992;34:979-84.

11 Raina Pet al. The health and well-being of caregivers of children with cerebral palsy. Pediatrics 2005;115:e626-36.

12 Guyard A, Michelsen SI, Arnaud C, et al. Family adaptation to cerebral palsy in adolescents: a European multicenter study. Res Dev Disabil 2017;61:138-50.

13 Kaya K, Unsal-Delialioglu S, Ordu-Gokkaya NK, et al. Musculoskeletal pain, quality of life and depression in mothers of children with cerebral palsy. Disabil Rehabil 2010;32:1666-72.

14 Luijkx J, van der Putten AAJ, Vlaskamp C. Time use of parents raising children with severe or profound intellectual and multiple disabilities. Child Care Health Dev 2017;43:518-26.

15 Chou Y-C, Chiao C, Fu L-Y. Health status, social support, and quality of life among family carers of adults with profound intellectual and multiple disabilities (PIMD) in Taiwan. J Intellect Dev Disabil 2011;36:73-9.

16 Tadema AC, Vlaskamp C. The time and effort in taking care for children with profound intellectual and multiple disabilities: a study on care load and support. Br J Learn Disabil 2010;38:41-8.

17 Carver CS. You want to measure coping but your protocol' too long: Consider the brief cope. Int J Behav Med 1997;4:92-100.

18 Given CW, Given B, Stommel M, et al. The caregiver reaction assessment (cra) for caregivers to persons with chronic physical and mental impairments. Res Nurs Health 1992;15:271-83.

19 Saban KL, Griffin JM, Urban A, et al. Perceived health, caregiver burden, and quality of life in women partners providing care to veterans with traumatic brain injury. J Rehabil Res Dev 2016;53:681-92.

20 Sandstedt P, Littorin S, Cröde Widsell G, et al. Caregiver experience, health-related quality of life and life satisfaction among informal caregivers to patients with amyotrophic lateral sclerosis: a crosssectional study. J Clin Nurs 2018;27:4321-30.

21 Sautter JM, Tulsky JA, Johnson KS, et al. Caregiver experience during advanced chronic illness and last year of life. J Am Geriatr Soc 2014;62:1082-90.

22 Maguire R, Hanly P, Hyland P, et al. Understanding burden in caregivers of colorectal cancer survivors: what role do patient and caregiver factors play? Eur J Cancer Care 2018;27:e12527.

23 Nijboer C, Triemstra M, Tempelaar R, et al. Measuring both negative and positive reactions to giving care to cancer patients: psychometric qualities of the caregiver reaction assessment (cra). Soc Sci Med 1999;48:1259-69.

24 Sola-Carmona JJ, López-Liria R, Padilla-Góngora D, et al. Factors associated with the anxiety, subjective psychological wellbeing and self-esteem of parents of blind children. PLoS One 2016;11:e0162294

25 Cohen CA, Colantonio A, Vernich L. Positive aspects of caregiving: rounding out the caregiver experience. Int J Geriatr Psychiatry 2002;17:184-8. 
26 Washington KT, Pike KC, Demiris G, et al. Gender differences in caregiving at end of life: implications for hospice teams. J Palliat Med 2015;18:1048-53.

27 Rousseau M-C, Baumstarck K, Khaldi-Cherif S, et al. Impact of severe polyhandicap on parents' quality of life: A large French crosssectional study. PLoS One 2019;14:e0211640.

28 Weldeslasie Hailemariam K. The psychological distress, subjective burden and Affiliate stigma among caregivers of people with mental illness in Amanuel specialized mental hospital. AJAP 2015;4:33

29 Fadden G, Bebbington P, Kuipers L. The burden of care: the impact of functional psychiatric illness on the patient's family. $\mathrm{Br} J$ Psychiatry J Ment Sci 1987;150:285-92.

30 Gutiérrez-Maldonado J, Caqueo-Urízar A, Kavanagh DJ. Burden of care and general health in families of patients with schizophrenia. Soc Psychiatry Psychiatr Epidemiol 2005;40:899-904.

31 Gebeyehu F, Sahile A, Ayalew M. Burden, social support, and life satisfaction among caregivers of children with intellectual disability: the case of Felege Abay and Shembt primary schools, Bahir Dar, Ethiopia. Int Q Community Health Educ 2019;39:147-53.

32 Hunt CK. Concepts in caregiver research. J Nurs Scholarsh 2003;35:27-32

33 Skantze K, Malm U, Dencker SJ, et al. Comparison of quality of life with standard of living in schizophrenic out-patients. Br J Psychiatry 1992;161:797-801.

34 Baumstarck K, Leroy T, Hamidou Z, et al. Coping with a newly diagnosed high-grade glioma: patient-caregiver dyad effects on quality of life. J Neurooncol 2016;129:155-64.
35 Boyer L, Baumstarck K, Alessandrini M, et al. Emotional intelligence and coping strategies as determinants of quality of life in depressed patient-caregiver dyads: an actor-partner interdependence analysis. Compr Psychiatry 2017;74:70-9.

36 Rousseau M-C, Baumstarck K, Leroy T, et al. Impact of caring for patients with severe and complex disabilities on health care workers' quality of life: determinants and specificities. Dev Med Child Neurol 2017;59:732-7.

37 Tiemensma J, Kaptein AA, Pereira AM, et al. Coping strategies in patients after treatment for functioning or nonfunctioning pituitary adenomas. J Clin Endocrinol Metab 2011;96:964-71.

38 Vanderwerker LC, Laff RE, Kadan-Lottick NS, et al. Psychiatric disorders and mental health service use among caregivers of advanced cancer patients. JCO 2005;23:6899-907.

39 Ruisoto P, Contador I, Fernández-Calvo B, et al. Exploring the association between optimism and quality of life among informal caregivers of persons with dementia - CORRIGENDUM. Int. Psychogeriatr. 2019;31:435.

40 Demiris G, Oliver DP, Washington K, et al. A Problem-Solving intervention for hospice family caregivers: a randomized clinical trial. J Am Geriatr Soc 2019;67:1345-52.

41 Caldwell J. Consumer-directed supports: economic, health, and social outcomes for families. Ment Retard 2006;44:405-17.

42 Jayachandran $S$. The roots of gender inequality in developing countries. Annu Rev Econom 2015;7:63-88. 